\title{
Perceived effects of overcrowding on the physical and psychological health of hostel occupants in Nigeria
}

\author{
Adekunle Anthony Adegoke, $\mathrm{PhD}$ \\ Department of Psychology Obafemi Awolowo University Ile-Ife, Nigeria.
}

\begin{abstract}
This paper examined the physical and psychological health effects of overcrowding among students living in the university hostels. It also explored the influence of age and gender on the perceived effects of overcrowding. The sample consists of 453 (248 males and 205 females) young adults drawn from seven halls of residence within the campus. The selected participants completed a questionnaire that assessed both the physical and psychological health status. The results showed that experience of overcrowding, loss of privacy, number officially allocated to the room and the total number of room occupants had significant joint effects on the physical and psychological health status of hostel occupants. It was also revealed that that the type of room had influence and contributed to the level of exposure to disease causing agents. Results also showed a significant influence of gender and age on perception of crowding effect.
\end{abstract}

\section{Introduction}

Crowding as a concept in environmental psychology is one of the three sub areas that comprise the literature on human spatial behaviour; the other two are interpersonal distancing and small-group ecology. Crowding is viewed as a situation in which individuals are confronted with environmental circumstances beyond their control. Stokols (1976) differentiate crowding from density, though the two concepts look similar. He opined that density is a necessary but not a sufficient condition for individuals to experience the feeling of being crowded. Levy and Herzog (1974) also attempted a distinction between crowding and density. The former is basically measured as either the ratio of persons to rooms or as the living area per person. The latter is measured as the number of persons residing within a standard area unit (square mile, square kilometers, acre, and hectare)..

Over the past three decades, the issue of crowding had received a substantial attention of social scientists. In general, much has been done in the area of its possible effects on human living. Researchers like Stokols, Walter and Resnick (1978); Baron, Mandel, Adam and Griffen (1976), Saegert (1978) have examined the impact of overcrowding and task performance of students. Rodin (1976) worked on household crowding and task performance among children. On stress and related variables, the contributions of Marsella, et al (1971) and Cohen (1977) were noteworthy. Crowding effects on interpersonal relations have been looked into by Freedman, Levy, Bucham and price (1972) while Hutt and Vaizey (1966) had documented report of group crowding on social behaviour of children. On sex difference, Freedman, et al, (1972) using a laboratory setting found that male subjects response unfavourably to increasing density while female response is favourable. Although there is substantive literature on effects of crowding on human health, most of the research findings show mixed results. Booth and Cowel (1976) study revealed that crowded household have very little or no effect on people's health. Stokols et al. (1978) study on perception of residential crowding, classroom experiences and students health indicates that residential crowding experiences promote medical problems and poor academic performance. They were of the opinion that although crowding has effects on health, it does not provide a basis for inferring causal connections between residential crowding and human health. Before then, Stokols et al, (1976) study among university students shows a strong relationship between the subjects perceived crowding and health.

Mitchell (1971) concluded from his Hong Kong study that while overcrowding produces superficial signs of psychological stress (complaining, unhappiness, worry) and certain problems relating to control of children, it does not cause deeper and more basic levels of emotional strain and hostility. Kalin and Perlin (1967) found that strains and irritations caused by overcrowding do precipitate a certain amount of minor mental illness, mainly psychoneurotic symptoms including a large component of somatisation but not related to the severe mental disorders which result in hospitalization . Gove, Hughes and Galle (1979) found that experience of crowding were associated with poor physical health by being strongly associated with getting insufficient sleep, catching infectious disease, having to do chores being unable to get a good rest and not being care for by others when sick.

In contrasts to these positive findings, Gale et al. (1972); Schoor (1966) opined that if crowding is related to physical health, it is because persons in crowded households are physically run down, more susceptible to 
infectious disease and when sick, are involved in a flow of activities, and consequently cannot get a good rest and are not cared for. Moge Schmitt (1966) from his epidemiological study of the city of Honolulu also tends to dismiss crowding as a significant correlate of measures of health and social disorganization. In the same direction, Edwards, Tuedore and Saruda (1994) study on the effects of both subjective and objective crowding on human living findings shows a possible factors contributing to deficiencies in psychological well-being, family relations, sexual relations and reproductive behaviour but no effects on health status, thus confirming the inconsistency of research findings to establish a concrete position on the effect of crowding on human health.

\section{Theoretical Perspectives}

The theoretical literature on the experience of crowding focuses on the two analytically oriented concepts; an excess of stimulation and a lack of privacy. For example, Dessor (1972) defines crowding as "receiving excess of stimulation from social sources". Other investigators who have emphasized stimulus overload in the experience of crowding are Rapport (1972), Gallet, Gove and Mepherson (1972), and Wohlwill \& Carson, (1972). A number of models and theories exists as to why crowding environment posses a great number of factors that incapacitate the normal functioning of the individuals. In such environment in which crowding is perceived (primary vs secondary or important vs consequential) and the source of interference on a setting perceived as "crowded" Neutral vs personal or intentional vs unintentional) will have a great impact on human responses and propositions seems to have important implications. For instance, household crowding among family members seems to be more serious than crowding in a setting such as an amusement park. Freedman (1975) attempted to replace the subjective-crowding model with the density-intensity theory. This notion suggests that high density makes good events better and bad events worse, acting as an enhancer, Stokols (1977b) countered these ideas with evidence that suggested that good events can deteriorate due to density. He argued that the crowding construct needs further development to explain the inconsistent results concerning arousal and stress.

Baldassare (1995) reported another model tagged "psychological stress model" of household crowding. This model raised the argument that objective household overcrowding conditions lead to the subjective experience of crowding, which in turn, results in psychological stress. It is the individual stress developed from such crowding experiences that leads to a number of deficiencies in family relations and personal well-being. Perhaps the best theoretical discussion of the effects of the environment on behaviour is that of Altman (1975). Altman, while recognizing the importance of stimulus over-load, feel that the concept of privacy is the key to understanding crowding. A modified version of subjective/objective model of crowding as proposed by Gove et al (1979) was employed in this study to examine and explain the nature of health consequences, associated with residential crowding among university students. The model is presented thus:

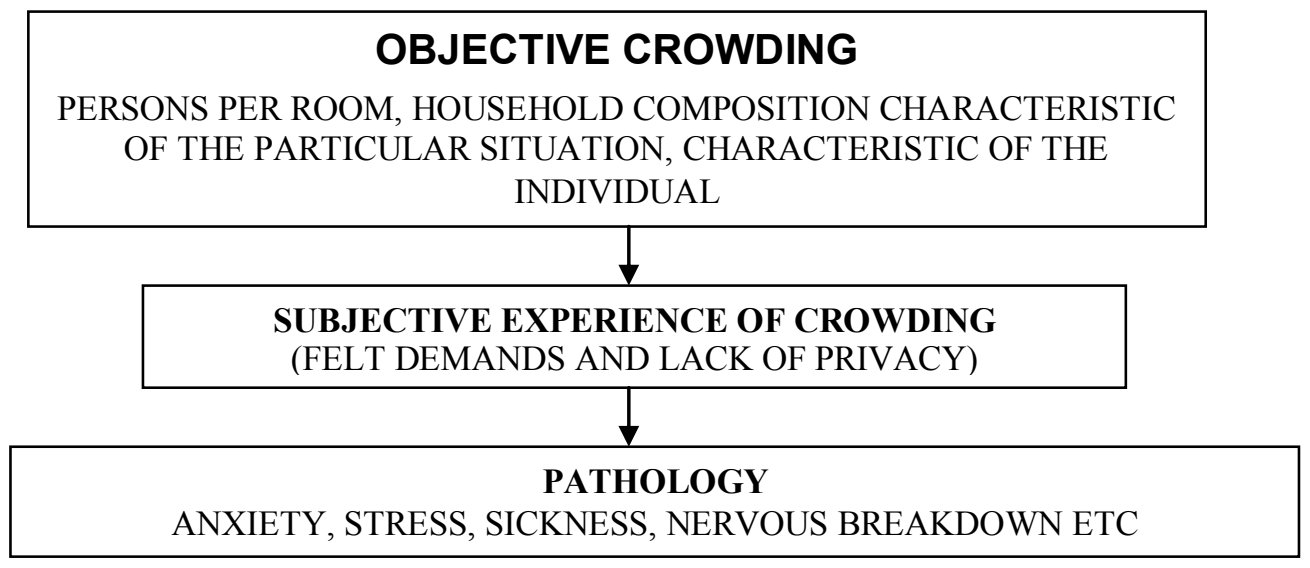

Source: Gove, et al, 1979

\section{Statement of the Problem}

The rate at which the world population is increasing with little or no associated rise in the resources needed to meet this upward trend call for examination of some of the consequences that such population explosion may have on human living. Despite the level of world civilization, it is not uncommon to find people living a dormitory life in a single room. This is in contrast with WHO conventional standard of one person per room (Marsella et al, 1971). As the number of students seeking admission into Nigerian universities increases, yearly the provisional structures put in place for conducive learning of which good housing is one tends to be in 
shortage of expected demand. As a result of inadequate funding which makes it impossible to provide adequate facilities to meet this demand, the available ones are being rationed among teeming population of students, thus giving rise to overcrowding and stretching of the facilities.

In most of Nigerian universities, it is not uncommon to see students sitting on bare floor to listen to lectures, placing their notebook on their laps, and more devastating is the over crowded situations being witnessed in their halls of residence. The university halls of residence that was initially designed to accommodate two students per room are now being officially allocated to nine students in some halls and six students in majority of the halls, with another possibility of occupants of such rooms accommodating as much as six squatters in the same single room, thereby raising the number of occupants to twelve or even fifteen in some rooms. In such arrangement, the room is overcrowded and congested, such that breathing air that ought to be free and accessible are now being competed for; personal space and privacy becomes a luxury and the risk of contracting infectious disease is increased. Basic sanitary facilities become a problem. About 120 to 150 students per floor of at least ten rooms competes for the use of four urinal bowls, bath showers and water closet system that ought to be for twenty students. One then needs to ask "Are there not possible effects of these experiences emanating from over crowding on the students" health as well as their social and psychological functioning. It is the focus of this study to examine some of the possible consequences.

\section{Justification for the study}

Considering the major role that health play in human functioning and the great importance attached to it, it becomes highly imperative to point attention to various possible factors that may hamper the course of healthy society being agitated for all over the world. With the current attention of medical and paramedical fields towards health promotion and maintenance, and efforts being geared towards prevention more than cure, this study contribute to this effort by exploring and exposing variables associated with residential crowding that may short-cut this goal. Moreover, a review of post 1960's and 1970's literature on human spatial behavior revealed that the incidence of crowding and population density cut across major develop and developing countries of the world and research focusing on its impact on human living have gulped a lot of human and financial resources, yet, the issue remains unclear especially one that concerns the effects of crowding on human health. Although most literature on crowding give insight into nature and its impact on human task performance, academic deficiencies, interpersonal relations and social pathologies, research studies on its effect on human health are with mixed results and inconsistence thus, making it inconclusive and reliable. This study examined this issue of crowding and health in a culture and setting different from previous studies so that further contributions can be made on the issue and progress can be made in the area

\section{Research Objectives}

The objectives of this study are to:

$\mathrm{i}$ to find out to possible health consequences associated with residential crowding as experienced and reported by University students residing in Halls of residence

ii to explore and examine the negative effects the crowding experiences may have on the psychological and mental functioning of the students living in such crowded environment.

iii to examine differences between single room occupants and multiple room occupants on the reported crowd induced physical and psychological health consequences.

iv to seek for possible influence of age and gender in the reported health and psychological consequences of overcrowding.

\section{Hypotheses}

The following null hypotheses were formulated and tested at 0.05 level of significance:

1. Experience of overcrowding will not have significant effect on physical health of hostel occupants.

2. Experience of overcrowding will not have significant effect on psychological health of hostel occupants.

.3. Type of room will not have significant influence on the physical and psychological health of hostel occupants.

4. Gender will have no significant influence on the experience of overcrowding, privacy and health status.

5. Age will have no significant influence on the experience of overcrowding privacy and health status 


\section{Method}

\section{Study Area}

The study is conducted among students Obafemi Awolowo University, Ile-Ife, Nigeria. The University is one of the federal government owned public universities in Nigeria. The university campus is a community of its own with student enrolment of over 30,000 and staff strength of about 4,000. The university was founded in 1962, and now one of the largest universities in Nigeria that draw its students from all the six geo-political zones in the country. The students are from all the three main tribes of Nigeria: Yoruba, Ibo and Hausa. Although it is located in the South West Yoruba speaking area of the country, the main lingua franca remain English language. For accommodation of students, the university has six undergraduate halls of residence that can accommodate about 9,450 students and one postgraduate hall that can accommodate about 700 students.

\section{Research Design}

Quasi-experimental descriptive design with no equivalent control group was used in this study. Two groups of students were studied: those who reside living in a multi-bedded room and those who are living in single-bedded room.

\section{Sample and Sampling Procedures}

All students of Obafemi Awolowo University residing in the halls of residence constitute the target population for this study. Four hundred and fifty three (248 males and 205 females) young adults participated in this study. They were selected from six undergraduate halls and one postgraduate hall. The study adopted a multistage sampling strategy. The halls of residence were stratified based on their designs (single bed, two-beds \& six beds), and each of the six halls constitutes a stratum from which rooms were selected and participants drawn. Systematic sampling technique was employed to select the rooms. The total number of rooms in each hall was divided into kth number to get the required sample size.

\section{Instrument}

The instrument for the study consists of a four page questionnaire divided into four sections. Sections one deals with the respondents' socio-demographic variables and section two addressed reported levels of crowding experience, items in section one and two were self-designed by the researcher based on the previous review of related works on the concepts. The third and fourth sections consists of items that measure physical health status and Awaritefe Psychological Index (API) which assessed the psychological health of the participants. Crowding as a concept in this study is operationalised by the measure (persons per room) (P/R) and conceptualized as the subjective experience of an excess social demands and/or lack of privacy.

\section{Results}

Table 1 presents the most frequently reported symptoms of physical illness. It ranges from catarrh to urinary tract infection (UTI). As observed, majority of these symptoms can be contracted through contact with others (Communicable Diseases) and are likely to be as a result of overcrowded environment

Table: 1 $\quad$ Mean Rank of Ten Most Frequently Reported symptoms of Physical Illness
\begin{tabular}{|lll|}
\hline Symptoms & Mean & Rank \\
\hline Catarrh & 8.50 & 1 \\
Insect bite & 7.72 & 2 \\
Malaria & 7.35 & 3 \\
Cough & 7.04 & 4 \\
Skin rash/itching & 6.88 & 5 \\
Cold/flu & 6.78 & 6 \\
Headache & 6.68 & 7 \\
Boils/keloid & 5.84 & 8 \\
Eczema & 5.77 & 9 \\
Urinary Tract Infection (UTI) & 5.45 & 10 \\
\hline
\end{tabular}

The list of the ten commonly reported symptoms of psychological malfunctioning and their mean rank is shown in Table 2. Most of the listed symptoms can be attributed to be signs of acute stress, resulting from pressure and demand of academic work. The generality of students living in the hostel lacks privacy and control over who comes to the room and when. These conditions limit the individual occupant to decide and plan the daily activities in the room. These often result to inadequate sleep, weakness and getting worried. 
Table 2: Mean Rank of the Ten most Commonly Reported Symptoms of Psychological health

\begin{tabular}{|lll|}
\hline Symptoms & Mean & Rank \\
\hline Loss of weight & 34.14 & 1 \\
Weakness (tiredness) & 32.16 & 2 \\
Poor sleep (inadequate sleep) & 31.20 & 3 \\
Always thinking & 31.17 & 4 \\
Feel lazy to get up from bed in the morning & & \\
Drowsiness (always feelings sleepy & 31.02 & 5 \\
Restless & & \\
Shyness & 29.90 & 6 \\
Stomach is turning (not comfortable & 29.53 & 7 \\
Worried & 28.70 & 8 \\
& 28.57 & 9 \\
& 28.50 & 10 \\
\hline
\end{tabular}

The result of the inter correlation among variables is presented in Table 3. There is significant relationship between psychological and physical health of the respondents $(\mathrm{r}=0.36, \mathrm{p}<0.001)$. Privacy is also correlated with psychological health; $(\mathrm{r}=0.24 ; \mathrm{p}<0.001)$, and physical health $(\mathrm{r}=0.19 ; \mathrm{p}<0.05)$. The experience of crowding is related to physical health $(\mathrm{r}=0.14 ; \mathrm{p}<0.05)$, number of people allocated to the room $(\mathrm{r}=0.95 ; \mathrm{p}<0.001)$, and number of occupants in each room $(r=0.46 ; p<0.001)$, but not to psychological health $(r=0.05 ; p>0.05)$.

Table 3: Intercorrelations Between Measured Variables

\begin{tabular}{|c|c|c|c|c|c|c|}
\hline & bles & 1 & 2 & 3 & 5 & \\
\hline 1. & Psychological & _- & & & & \\
\hline 2. & Physical health & $0.36 * *$ & - & & & \\
\hline 3. & Privacy & & $0.24 * *$ & $0.19 * *$ & - & \\
\hline 4. & Crowding & & 0.05 & $0.14 *$ & 0.04 & - \\
\hline 5. & No Allocated & 0.04 & 0.09 & 0.05 & 0.71 & - \\
\hline 6. & Number of Occupants & 0.05 & 0.11 & 0.03 & $0.95^{* *}$ & $0.46^{* *}$ \\
\hline
\end{tabular}

$* \mathrm{P}<0.05 ; * * \mathrm{P}<0.001$

Table 4 presents the result on hypothesis one. The regression analysis showed that experience of overcrowding, loss of privacy, number officially allocated to the room and the total number of room occupants had significant joint effects on the physical health status of hostel occupants $\left[\mathrm{R}=0.26 ; \mathrm{R}^{2}=0.07 ; \mathrm{F}(4,239)=4.19 ; \mathrm{p}=.003\right]$. Individual experience of overcrowding $[\mathrm{t}(243)=2.39, \mathrm{p}=0.018]$, privacy $[\mathrm{t}(243)=2.68 ; \mathrm{p}=0.008]$; and total number of room occupants $[\mathrm{t}(243)=2.28, \mathrm{p}=0.026]$ had significant effects on the physical health of hostel occupants.

Table 4: $\quad$ Regression Analysis for Privacy, Hostel Crowding, Number of Officially Allocated and Occupants Rooms on Physical Health

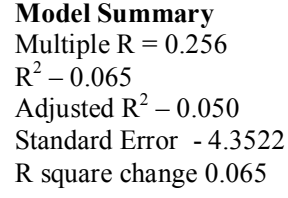

\begin{tabular}{|clllll|}
\hline Model & Sum of Squares & df & Mean Square & F & Sig. \\
Regression & 317.198 & 4 & 79.300 & 4.19 & $.003^{\mathrm{a}}$ \\
Residual & 4527.064 & 239 & 18.942 & & \\
Total & 4844.262 & 243 & & & \\
\hline
\end{tabular}




\begin{tabular}{|lllcc|}
\hline & & & & Sig. \\
Model & B & Std. Error & T & .0 .81 \\
(Constant) & 15.497 & & 2.677 & .000 \\
Privacy & .185 & 2.189 & 2.385 & .008 \\
Crowding & .434 & .069 & -1.867 & .063 \\
No of Students & & & & \\
Officially Allocated & -.381 & .204 & -2.277 & .026 \\
to rooms & & & - & \\
Total No of Room & -424 & .186 & & \\
Occupants & & &
\end{tabular}

The regression analysis for hypothesis two shown in Table 5 revealed a significant joint effects of experience of overcrowding, privacy, number allocated to the room and total number of room occupants on the psychological health of hostel occupants $\left[R=0.36 ; R^{2}=0.13 ; F(5,202)=5.86 ; p<0.001\right]$. However, individual experience of overcrowding $[\mathrm{t}(207)=0.149 ; \mathrm{p}=0.882]$; privacy $[\mathrm{t}(207)=1.20 ; \mathrm{p}=0.232]$; and total number of room occupants $[\mathrm{t}(207)=0.35 ; \mathrm{p}=0.727]$ had no significant effect on psychological health of hostel occupants

Table 5:Regression analysis of Privacy, Physical Health Satus, Hostel Crowding, Number Officially Allocated and Occupants on Psychological Health.

\section{Model Summary}

Multiple $\mathrm{R}=0.356, \mathrm{R}^{2}=0.127$, Adjusted $\mathrm{R}^{2}-0.105, \mathrm{R}$ square change -0.127

Standard error. $=16.63$

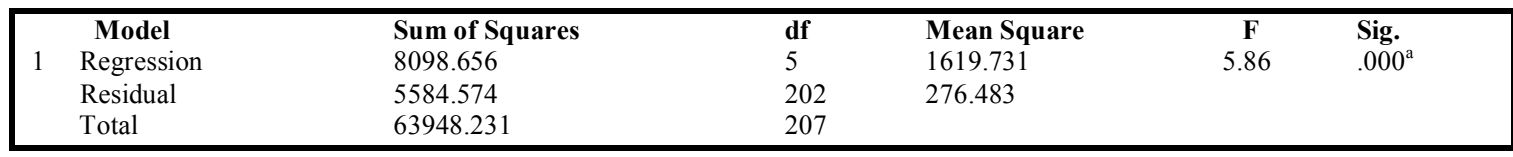

\begin{tabular}{|c|c|c|c|c|}
\hline Model & & & & Sig \\
\hline & B & Std. Error & $\mathbf{T}$ & \\
\hline (Constant) & 38.547 & 10.295 & 3.74 & .000 \\
\hline Health status & 1.260 & .268 & 4.69 & .000 \\
\hline $\begin{array}{l}\text { Crowding } \\
\text { No of Students }\end{array}$ & -114 & .765 & -.149 & .882 \\
\hline $\begin{array}{l}\text { Officially Allocated } \\
\text { to rooms } \\
\text { Total No of Room }\end{array}$ & -148 & .845 & -.176 & .861 \\
\hline Occupants & .273 & .781 & .350 & .727 \\
\hline Privacy & .352 & .294 & 1.20 & .232 \\
\hline
\end{tabular}

On hypothesis three, findings from this study revealed that the type of room had influence and contributed to the level of exposure to disease causing agents. It was shown that subjects from one-bedded room had the least symptoms of disease and illness. When compared with subjects residing in 3-bedded, 6 - bedded, 9-bedded and 12-bedded respectively. The highest complaints/ symptoms was recorded among those subjects who dwelt in 12- bedded rooms. One way Analysis of Variance(ANOVA) showed a significant effect of room type on physical symptoms of disease and illness; $[F(4,297)=3.46 ; p=0.009]$. Respondents' assessment of level of crowding in the room was also found to be significantly related to their perception of crowding effects ( $F$ $(2,425)=26.53 ; \mathrm{p}<0.001)$, Privacy $(\mathrm{F}(2.287)=19.13 ; \mathrm{p}<0.001)$ but not for Health status of the room occupants $(\mathrm{F}(2.298)=2.47 ; \mathrm{p}>0.087)$. The results revealed that crowding effects was more pronounced among subjects who perceived the room as overcrowded $(\mathrm{m}=30.26 ; \mathrm{SD}=18.53)$ compared with those subjects who rated the room situation as normal $(\mathrm{m}=16.68 ; \mathrm{SD}=7.36)$. The same trends were observed for privacy. Participants who rated the room condition as normal believed they have more privacy than subjects who rated the room condition as overcrowded.

Result on hypothesis four which assessed influence of gender revealed significant sex difference for perception of crowding effects more for female than male subjects [ $t(398)=-4.04 ; p<0.001]$. Female mean score (28.39) and standard deviation (17.02) were found to be significantly different from male mean score (22.26) with standard deviation of (13.19). It appears that Male generally possess the skills to adjust more in social interaction than females counterpart that involves same sex. However, there were no sex difference for Privacy,[ $\mathrm{t}(459)=0.08 ; \mathrm{P} \geq 0$. 079]; and Health status,[ $\left.\mathrm{t}(284)=-1.67^{\prime} \mathrm{p}=0.096\right]$; proving that there was no 
significant sex difference on the assessment for privacy and health status. For hypothesis five on age difference in crowding, health status and privacy, the results obtained showed a significant age difference for perception of crowding effects $[. F(3,416)=4.48 ; p<0.004]$. Further probing revealed that scores on crowding effects inversely rose with age. The least mean score (20.33) and standard deviation (8.83) was observed among (26 and above) age group while the highest mean score (29.79) and standard deviation (1882) was found among age group (1618 years). The trend for other two age groups followed the patterns observed for the least and highest age groups. There was no significant age difference for privacy and health status.

\section{Discussion}

In this study, a number of crowd induced health issues have been raised. The identification of the most reported symptoms of physical illness such as Cattarh, Malaria, cough, skin rash, cold/flu, urinary tract infections (UTI) are possible diseases that can be contracted in an overcrowded environment. Most of them are air-borne infectious diseases which are easily distributed once there is congestion of human population. In situation where people are overcrowded, the resources available to them may not be sufficient, hence, people tends to compete for limited resources. In such condition where people of different genetical and environmental background are brought to live under the same roof, dwells together, share their things together, a lot of social, psychological and health consequences may emanate from such living arrangement. Such overcrowded environment with little or no sanitary measures provides avenue for epidemiological development and spreading of contagious and infectious diseases. Residential crowding has been linked both with physical illness, including infectious diseases such as tuberculosis and respiratory infections( Krieger and Higgins,2002), and with psychosocial distress among both adults and children; children who live in crowded housing may have poorer cognitive and psychomotor development or be more anxious, socially withdrawn, stressed or aggressive(Evans, 2006) A number of studies indicate that crowded conditions (measured in terms on the number of people per household) are associated with increased incidence of colds, asthma, influenza and diarrhea, particularly in young children (Kearns et al, 1992; Causon-Kaas et al, 1997). Elender et al (1998) studied risk factors for tuberculosis in England and Wales and found that rates were significantly higher in households with more than one person per room.

This finding corroborate the work of Bradley, et al, (1992) who noted that illness such as whooping cough, polio, diarrhea, malaria, meningitis, acute lower respiratory infections and stress may be related to over crowding. It has also been established that transmission of disease increases among people living closely together (UNCHS, 1995:6). Specifically, the report attests that overcrowding increases the risk of infection as the number of potential transmitters is increased. Lack of privacy, number of hostel occupants and overcrowding had significant negative effect on the physical and psychological health status of the respondents. The higher risks of infection lead to infection at a younger age which, in turn, is a determinant of severity and fatality of the disease.. Overcrowding is also considered to increase the risk of, in particular, the long-term adverse effects of infections (UNCHS 1995:7-8). Plausible evidence abound that crowding may have a detrimental effect on health. Findings from studies indicate that crowding is associated with increases in blood pressure (D'atri, 1975; Evans, 1979) and increased secretion of stress hormones (Lundbergh, 1976), in the short term, at least. Fuller et al (1993) identify two reasons why crowded conditions may be detrimental to health: first, the stress associated with crowding may depress the immune system and have other direct health effects; second, overcrowded conditions may facilitate the spread of communicable diseases.

Overcrowding, as revealed in this study has significant influence on the psychological state and health of hostel occupants. Among the most commonly reported symptoms, poor sleep, loss of weight, lethargy, lack of privacy, restlessness, and worry are found to have negative effects on the psychological functioning of the respondents. Gove, Hughes and Galle (1979) findings is one of the most widely quoted studies on crowding and psychological health. This large cross-sectional study revealed a strong relationship between crowding (persons per room) and poor mental health. The authors developed a series of scales to measure mental health, social relations in the home, physical health and care of children. Among other things, Gove et al(1979) concluded that: crowding results in physical withdrawal, psychological withdrawal, a lack of general planning behaviour and a general feeling of being "washed out", and that the experience of crowding is strongly related to poor mental health and to poor social relationships in the home. The finding on effects of overcrowding on psychological health gain support of Edwards, et al, 1994; who found that both objective and subjective crowding contributes to deficiencies in psychological well-being. A previous study by Kalin and Perlin (1976) had long found that strains and irritation caused by overcrowding do precipitate certain amount of minor mental illness, mainly psychoneurotic symptoms. The link between experience of crowding and associated poor psychological health had also been documented by Gove, et al (1979). The inability to get sufficient sleep, good rest, and not being cared for by others when sick were established. The psychological effects of overcrowding are interlinked with social effects. Overcrowding contributes to psychological frustrations which, in turn, have a bearing on behavioural responses and one's ability to cope with the conditions. 
It has also been noted that people who feel crowded for prolonged periods of time can become psychologically demoralized, depressed and anxious (Lepore, 1994). Individuals with experience of crowding often exhibit a pattern of somatic and social reactions in addition to their psychological reactions. . Overcrowding, generally, is considered a chronic stress which exacerbates other stresses. Baum and Koman (1976) study of the psychological effects of social and spatial density found that people living in high social destiny environments were more likely to become socially withdrawn, while responses to spatial density include aggressive behavior.

On gender impact on hostel resident's level of satisfaction, Walden et, al (1981) found that males and females tend to have different perceptions on the 'feeling of crowding' and subsequently have different coping strategies to the crowded conditions. Gove and Hughes (1983) also found that crowding has a greater effect on mental health for women. Gove and Hughes assert that the subjective experience of overcrowding is determined by too many social demands and a lack of privacy, and that the experience of these interferes with one's behaviour and mental health. Fuller et al., (1996) study of psychological well-being and household overcrowding in Thailand considers crowding as a chronic stress which is accompanied by lack of privacy. It was found that wives who feel they lack privacy are more likely to contemplate suicide. A study by Qouta, et al. (1997) on the metal health effects of house demolition in Gaza concludes that in traumatic conditions women's mental health is especially vulnerable. The nature of the traumatic experience determines the extent and nature of psychological problems

\section{Conclusion}

From the findings from this study, it can be concluded that overcrowding has significant negative effects on both the physical and psychological health of hostel occupants. The type of room and being female also impact significantly on the residents health.

\section{References}

[1]. Altman, I. (1975) The Effects of Crowding and Social Behaviour, Brooks/Cole Publishing Co., California.

[2]. Baldassare, M. (1978). Humna Spatial behaviour: Annual Review of Sociology: 4;29-56 Baldassare, M. (1988) Residential crowding in the United States: A review of the research, Handbook of Housing and the Built Environment in the U.S.

[3]. Baldassare, M. (1995). Household crowding and its consequences: Book review Baron, R.; Mandel, D; Adam; C.;Giffen, L. (1976). Effects of Social Density on University Students. Journal of Personality and Social Psychology. 34;434-446.

[4]. Baum, A. and Koman, S (1976). "Differential response to anticipated crowding: psychological effects of social and spatial density," Journal of Personality and Social Psychology, 34 (3):526-36.

[5]. Baum. A.J, et al (1978) Crowding and Personal Control: Social density and the development of learned helplessness Journal of Personality and Social Psychology 21:79-83.

[6]. Booth, A., Cowell, J. (1976) 'Urban crowding and health', Journal of Health and Social Behaviour, 17, 204-220.

[7]. Booth, A. and Cowell, J. (1976). The effects of crowding upon Health. Journal of Health and Social Behaviour 17:204-220.

[8]. Bradley, D., Stephens, C., Harpham, T., and Cairn Cross S. (1992). A Review of Environmental Health Impacts in Developing Country Cities. The World Bank, p. 6.

[9]. Clauson-Kaas, Jes, et al. (1996). "Urban health: human settlement indicators of crowding," Third World Planning Review, 18 (3), pp.349-63.

[10]. Clauson-Kaas, J., Dzikus, A., Surjadi, C., Jensen, H., Hojlyng, N., Aaby, P., Baare, A. and Stephens, C. (1997)Crowding and Health in Low-Income Settlements, United Nations Centre for Human Settlements (Habitat), Avebury, England.

[11]. Cohen, S. (1977). Environments load and the allocation of attention. In advance in Environmental Research (Ed.) Baum, A. et al Norwood, N.J Ebrlbaum Press.

[12]. Desor, J.A. (1972). Toward a Psychological theory of Crowding. Journal of personality and Social Psychology 21; 79-83

[13]. Edwards, J.N., and Both, A. (1977). "Crowding and human sexual behavoir," Social Forces, 55 (3):791-808.

[14]. Edwards, J., Fuller, T. Sermsi, S., and Vorakitphokatorn, S. (1994) Household Crowding and Its Consequences, Westview Press, Colorado.

[15]. Elender, F., Bentham, G. and Langford, I. (1998) Tuberculosis mortality in England and Wales during 1982-1992: Its association with poverty, ethnicity and AIDS, Social Science Med. Vol. 46 (6):673-681.

[16]. Evans,G.W.(2006) Child development and the Physical Environment. Annual review of Psychology, 57: 423-51

[17]. Freedman, J.L; (1975). Crowding and Behaviour. San Francisco Freeman. Freedman, J.L: Levy, R.W.; Buchanan and Price, J. (1972). Crowding and Human aggression Journal of Experimental Social Psychology 8:528-548.

[18]. Fuller, T. D., Edwards, J.N., Sermsri, S. and Vorakitphokatorn, S. (1993) Housing, stress and physical well-being: Evidence from Thailand, Social Science Medicine Vol. 36, 11, 1417-1428.

[19]. Fuller, Theodore D., et al. (1996). "Chronic stress and psychological well-being: evidence from Thailand on household crowding," Social Science Medicine, 42 (2), pp. 265-80

[20]. Galle, O.. Gove, W.R; McPherson J.M. (1972). Population density and Pathology; what are the relationships for man? Science: $176 ; 23-30$.

[21]. Gove, W.R.; Hughes,. M. and Galle, O.R (1979). Overcrowding in the home: An empirical investigation of its possible pathological consequences. American Sociological Review Vol. 44 (Feb), 59-80.

[22]. Gove, Walter R. and Hughes, Michael (1983). Overcrowding in the Household: An Analysis of Determinants and Effects. Toronto and New York: Academic Press.

[23]. Hutt, C, and Vaizey, M. (1966). Differential effects of group density on social behaviour. Nature 209; 1371-1372.

[24]. Kearns, R. A., Smith C. J. and Abbott, M. (1992) The stress of incipient homelessness, Housing Studies Vol. 7 No 4 280-298.

[25]. Krieger, J and Higgins, D.L.(2002) Housing and Health: Time again for public health action. American journal of Public Health,92(5): 758-68

[26]. Lepore, S. J. (1994). Crowding: e! ects on health and behavior.In V. S. Ramachandran (Ed.), Encyclopedia of Human Behavior, Vol. 2. San Diego, CA: Academic Press, pp. 43-51. 
[27]. Levy, L. and Herzog, A.N. (1974), Effects of Population Density and crowding on Health and Social Adaptation in the Netherlands. Journal of Health and Social Behaviour 15:228-240.

[28]. Marsella A. J., Escudero M. and Gordon P. (1970) The effects of dwelling density on mental disorders in Filipino men. J. Hlth Soc. Behav. 11, 288.

[29]. Mitchell, R.E. (1971). Some Social Implications of High Density Housing. American Sociological Review: 36;1829.

[30]. Morgan, Griscom (1972). "Mental and social health and population density," Journal of Human Relations, 20 (1-2):196-204

[31]. Qouta, Samir, Punamaki, R-L., and El Sarraj, E. (1997). "House demolition and mental health: victims and witnesses," Journal of Social Distress and the Homeless, 6 (3):203-11

[32]. Rodin, J. (1976). Crowding, Perceptive Choice and Response to Controllable and Uncontrollable Outcomes Journal of Experimental Social Psychology 12:564-578.

[33]. Saegert, S. and McCarthy, D. (1978). Residential Density, Social Overload, and Social withdrawal. Human Ecology Vol. 6(3), 253272 .

[34]. Schmitt, R.C. (1966). Density, Health and Social Disorganization. Journal of the American Institute of Planners. 32;38-40

[35]. Stokols, D. (1976). The Experience of Crowding in Primary and Secondary Environments. Environmental Behaviour 8; 49-86.

[36]. Stokols, D. (1977b). In Defense of the Crowding Construct. In Baum, A. et al. (Eds). Advances in Environmental Psychological. Hillsdale, New Jersey.

[37]. Stokols, D., Walter, O. and Resnick, S.M (1978). Perception of Residential Crowding, Classroom Experiences and Students Health. Human Ecology. Vol. 6(3), 1978.

[38]. UNCHS (Habitat) (1995). Human Settlement Interventions Addressing Crowding and Issues. Nairobi

[39]. Walden,T.A., Nelson, P.A., \& Smith, D.E.(1981). Crowding, Privacy, and coping. Environment and Behaviour, 13(2): 20-224

[40]. Wohlwill, F., and Carson, D.H.(1972) Environment and the social sciences: Perspectives and applications: Washington D.C. American Psychological Association. 